\section{俩 Heighten Science \\ P U B L I C I T I O N S Corporation \\ ISSN \\ 2573-7724}

\title{
Hyperthermia and Breast cancer: A short review
}

\author{
Bora Uysal* \\ Gulhane Education and Research Hospital, Radiation Oncology Department, Etlik Kecioren \\ Ankara, Turkey
}

\begin{abstract}
*Address for Correspondence: Bora Uysal, Gulhane Education and Research Hospital, Radiation Oncology Department, Etlik Kecioren Ankara, Turkey, Tel: 031230446 89, Email: drborauysal@windowslive.com
\end{abstract}

Submitted: 12 October 2017

Approved: 16 October 2017

Published: 17 October 2017

Copyright: @ 2017 Uysal B. This is an open access article distributed under the Creative Commons Attribution License, which permits unrestricted use, distribution, and reproduction in any medium, provided the original work is properly cited.

Keywords: Hyperthermia; Breast cancer; Chemotherapy, Radiotherapy

\section{Abstract}

The main goal of hyperthermia is to elevate the tumor temperature to kill tumor cells and improve local control. The usage of hyperthermia is combination with radiotherapy or chemotherapy. Hyperthermia is delivered in different types of cancers like breast cancer, melanoma and sarcoma. Breast cancer treatment enroll surgery, chemotherapy, radiotherapy and hormone therapy. Hyperthermia is given once or twice a week concomitantly with radiotherapy or chemotherapy. This short review will enlight the types, physics, and the results of hyperthermia especially in the management of breast cancer therapy.

\section{Introduction}

Hypertermia (HT) is a radiosensitizer and also a cytotoxic treatment modality. HT inhibits lethal damage and sublethal damage repair. Different devices are used but no gold standart equipment is advised by authorities. HT kills tumor cells itself or sensitize them for the treatment outcomes for chemotherapy and radiotherapy. Thermotolerance is a special condition that immune response occurs against tumor cells after usage of HT.

\section{Combination of hyperthermia and chemotherapy}

Cisplatin, cyclophosphamide, bleomycin and mitomycin C have synergistic effects with HT. Firstly HT inhibits repair and increase DNA damage, cellular uptake of medicines and free radicals. It also helps to prevent from drug resistance. Optimal timing of HT and chemotherapy usage is not known but 5-FU and HT can be given simultaneously or be given before HT. Current data is not all but some drugs have synergistic interaction with HT. Trimodality treatment enrolls HT, radiotherapy and chemotherapy (Table 1).

\section{Concomitant usage of radiotherapy and hyperthermia}

G2 and M phase of cell cycle is radiosensitive and S phase is radioresistant. The cells in S phase start to be radiosensitive after HT. Reoxygenation with HT leads good response with radiotherapy (RT) because hypoxic cells are so radioresistant. HT blocks

Table 1: Studies of combination of hyperthermia with radiotherapy, chemotherapy and immunotherapy.

\begin{tabular}{|c|c|c|}
\hline Immunotherapy and hyperthermia & $\begin{array}{c}\text { Chemotherapy and hyperthermia } \\
\text { Takeda (2013) }\end{array}$ & $\begin{array}{c}\text { Radiotherapy and hyperthermia } \\
\text { Oldenborg (2015) }\end{array}$ \\
\hline & Yamamoto (2015) & Linthorst $(2015,2016)$ \\
\hline & & Refaat (2015) \\
\hline & & Van der Zee (1999, 2010) \\
\hline & & Varma (2012) \\
\hline & & lemwananonthachai (2003) \\
\hline
\end{tabular}

How to cite this article: Uysal B. Hyperthermia and Breast cancer: A short review. J Radiol Oncol. 2017; 1: 079-082. https://doi.org/10.29328/journal.jro.1001011 
lethal and sublethal damage pathways TER (thermal enhancement ratio) is a ratio of the needed doses with just radiotherapy and combined RT and HT to get an isoeffect. Although HT and RT improve local control when combined, the complications as bone necrosis, fibrosis or fistula should be known (Table 2).

\section{Physics}

The definition of HT is to elevate tumor temperature between 40 and 45 centigrad degree for one hour. The final effect doesnt occur same in very tissue because of the location containing fat, water or bone.

HT can be delivered via three modalities. Ultrasound, thermal conduction and nonionizing electromagnetic radiation are the major devices used for HT.

\section{Ultrasound}

Simply, the transfer of energy from acoustic field device to selected location is ultrasound heating. Superficial tissue is heated with ultrasound but some anatomic areas in body don't let the physicians to achieve better results. This problem limits the use of ultrasound. Superficial and deep heating devices can be used but care should be taken not to cause a complication of the bone or the other tissues especially in deep heating.

\section{Thermal conduction}

Thermal conduction is delivered with needle, surface pad or catheter that hot water circulating in. $0.5-30 \mathrm{mhz}$ radiofrequency electrodes are used for interstitial heating. This method is highly selective, sensitive and also give inhomogeneous dose to the tissue like brachytherapy. The popularity of thermal conduction is limited because of a decreasing usage of brachytherapy devices.

\section{Clinical hyperthermia}

Supraphysiologic elevation of temperature to the 40-45 centigrad degree in 1 hour is mostly known definition of HT. Firstly, HT had been used for metastatic tumors There are several trials enrolling HT and chemoradiotherapy or radiotherapy combinations. Esophagus, bladder and sarcomas are the locations of usage of chemoradiotherapy and HT combination and head and neck, melanoma, breast, brain, cervix, rectal, bladder and nasopharynx cancer are the locations of usage of radiotherapy and HT combination [1].

\section{HT in the treatment of breast cancer}

It is known that breast cancer is the most frequent malignancy among women. Chemotherapy and also radiotherapy are used in the management of breast cancer according to the stage and other factors.

\section{Discussion}

Hyperthermia-integrated chemotherapy is a new milestone for effective treatment [2]. The local recurrence years after locoregional and systemic therapy of breast cancer is a challenging issue to be discussed. In a article by Oldenborg et al., 8x4 Gy or 12x3 Gy was delivered combined with HT once or twice a week. HT and reirradiation resulted with effective and outstanding palliative in these group [3].

\begin{tabular}{|c|}
\hline Table 2: Types of Hyperthermia. \\
\hline \\
\hline \\
Ricrowave \\
\hline Ultrasound waves \\
\hline Infrared \\
\hline Laser \\
\hline Magnetic induction \\
\hline
\end{tabular}


HT and RT modalities were used in unresectable local recurrences and concomitant usage improved local control rates with slightside effects. The dose delivered for RT was 32 Gy in 4 fractions and HT was given once a week in this period [4]. Animal studies have been done for the evaluation of different $\mathrm{T}$ modalities by Petryk et al. Magnetic nanoparticle and microwave hyperthermia were compared and nanoparticle treatment resulted in slightly better effective and reduced normal tissue damage than microwave HT [5].

36 reconstructed breast cancer patients treated with reirradiation and HT were examined for the toxicities and grade 2 and 3 toxicity were seen in 7 patients and just one needed reoperation. This data showed that RT and HT can be an effectve and safe option in reconstructed breast cancer patients [6]. HT and chemotherapy combination was used for the management of advanced recurrent breast cancer study group and it was tolerable and efficient according to the results of Yamamoto et al, [7]. Refaat et al. studied HT and RT for 127 locally advanced or recurrent breast cancer patients. HT was delivered twice a week after RT. The effectiveness was showed and local control and also overall survival were improved compared to historical results with only RT [8]. The efficiency of HT in the management of unresectable skin metastases was shown in a 66-year-old female. HT actually have a supraadditive effect on RT and chemotherapy in this case. The tumor became nearly flat after HT [9].

Combination of HT and RT appear to have higher complete response rates compared to only RT modality. Totally 32 Gy of 8 fractions was delivered and 4 or 8 HT sequences were given concomitantly. Superficial hyperthermia was used with $433 \mathrm{MHz}$ [10]. In an article by Takeda et al., recurrent or advanced stage breast cancer patients were treated with immunotherapy, HT or combination of both. 23 of 712 patients have better outcomes with combination [11]. The usage of HT and RT improves local control. Randomised comparison of chest wall HT in heated and nonheated sectors was studied by Varma et al. Locally advanced berast cancer patients enrolled in this study. Same dose was given for all. No difference in late toxicity was shown after all between these groups [12].

HT gives better palliative results if combined with RT for recurrent breast cancer patients. This is associated with local control and radiosensitization of tumor by HT. Local control rate was $73 \%$ in this last study by Van der Zee [13]. The timing of HT differs in neoadjuvant, definitive and adjuvant treatment of breast cancer [14]. Ulcerative advanced breast cancer patients are a challenging issue because of the management. 12 of cases were treated with HT in 43 centigrad degrees and 20-70 Gy RT. Palliation and slightly local control were resulted after combination of therapies [15]. Usage of HT depends on clinical basis. In a study by Ben-Yosef et al, 2 patients were treated with HT adjuvantly. One of them has a positive deep surgical magrin and the other has second local recurrence in chest wall [16]. IMRT and HT combination started to be used in some centers and it is encouraging to see these modalities to enlight the future studies [17].

\section{Conclusion}

In this short review, HT was discussed with current literature. It is crystal-clear that not all but some oncology institutions have HT devices. HT is needed to have experts as oncologists and also technicians. Breast cancer treatment is vital because of frequency and the treatability of this type of cancer. Local control is improved with combinations of HT, RT and chemotherapy and there is a tendency to get better results for survival curves in the future. 


\section{References}

1. Halperin EC, Perez CA, Brady LW. Hyperthermia. Principles and practice of Radiation Oncology Fifth Edition. Wolters KluwerLippincott Williams \& Wilkins. 2008; 637-668.

2. Zhou Y, Sun J, Yang X. Molecular imaging-guided interventional hyperthermia in the treatment of breast cancer. Biomed Res Int. 2015: 505269. Ref.: https://goo.gl/YoP4nE

3. Oldenborg S, Griesdoorn V, Van R, Kusumanto YH, Oei BS, et al. Reirradiation and hyperthermia for irresectable locoregional recurrent breast cancer in previously irradiated area: size matters. Radiother Oncol. 2015; 117: 223-228. Ref.: https://goo.gl/evVpYQ

4. Linthorst M, Baaijens M, Wiggenraad R, Carien Creutzberg, Wendimagegn Ghidey, et al. Local control rate after the combination of re-irradiation and hyperthermia for irresectable recurrent breast cancer: results in 248 patients. Radiother Oncol. 2015; 117: 217-222. Ref.: https://goo.gl/7Pfn6D

5. Petryk AA, Giustini AJ, Gottesman RE, Trembly BS, Hoopes PJ. Comparison of magnetic nanoparticle and microwave hyperthermia cancer treatment methodology and treatment effect in a rodent breast cancer model. Int J J Hyperthermia. 2013; 29: 819-827. Ref.: https://goo.gl/PG5a24

6. Linthorst M, Van Rhoon GC, Van Geel AN, Margreet Baaijens, Wendy Ghidey. The tolerance of reirradiation and hyperthermia in breast cancer patients with reconstructions. Int J Hyperthermia. 2012; 28: 267-277. Ref.: https://goo.gl/ecZkgV

7. Yamamoto C, Yamamoto D, Tsubota Y, Sueoka N, Kawakami K, et al. Local microwave hyperthermia for advanced or recurrent breast cancer. Gan To Kagaku Ryoho. 2015; 42: 1231-1233. Ref.: https://goo.gl/Xt73hh

8. Refaat T, Sachdev S, Sathiaseelan V, Helenowski I, Abdelmoneim S, et al. Hyperthermia and radiation therapy for locally advanced or recurrent breast cancer. Breast. 2015; 24: 418-425. Ref.: https://goo.gl/e8bdhE

9. Yamamoto D, Inui T, Tsubota Y, Sueoka N, Yamamoto C, et al. The utility of hyperthermia for local recurrence of breast cancer. World J Surg Oncol. 2012; 10: 201. Ref.: https://goo.gl/62BMuN

10. Van Der Zee J, De Bruijne M, Mens JW, Ameziane A, Broekmeyer-Reurink MP, et al. Reirradiation combined with hyperthermia in breast cancer recurrences: overview of experience in Erasmus MC. Int J Hyperthermia. 2010; 26: 638-648. Ref.: https://goo.gl/kvst77

11. Takeda $\mathrm{T}$, Etani $\mathrm{M}$, Kobayashi $\mathrm{S}, \mathrm{Takeda} \mathrm{H}$. The effect of immunotherapy and hyperthermia on patients with advanced or recurrent breast cancer. Gan To Kagaku Ryoho. 2013; 40: 1596-1599. Ref.: https://goo.gl/SDXie8

12. Varma S, Myerson R, Moros E, Taylor M, Straube W, et al. Simultaneous radiotherapy and superficial hyperthermia for high-risk breast carcinoma: a randomised comparison of treatment sequealae in heated versus non-heated sectors of the chest wall hyperthermia. Int J Hyperthermis. 2012; 28: 583590. Ref.: https://goo.gl/V4zPTe

13. Van Der Zee J, Van Der Holt B, Rietveld PJ, Helle PA, Wijnmaalen AJ, et al. Reirradiation combined with hyperthermiain recurrent breast cancer results in a worthwhile local palliation. $\mathrm{Br} \mathrm{J}$ Cancer. 1999; 79: 483-490. Ref.: https://goo.gl/AxAvyA

14. Zagar TM, Oleson JR, Vujaskovic Z, Dewhirst MW, Craciunescu OI, et al. Hyperthermia for locally advance breast cancer. Int J Hyperthermia. 2010; 26: 618-624. Ref.: https://goo.gl/gCtEMB

15. Iemwananonthachai $N$, Pattaranutaporn $P$, Chansilpa $Y$, Sukkasem M. Hyperthermia in combination with radiation therapy for treatment of advanced inoperable breast cancer. J Med Assoc Thai. 2003; 86: 715-721. Ref.: https://goo.gl/uqcmN7

16. Ben-Yosef R. Hyperthermia combined with radiation therapy in the treatment of cancer patients. Harefuah. 2002; 141: 418-421.

17. Moros EG, Penagaricano J, Novak P, Straube WL, Myerson RJ. Present and future technology for simultaneous superficial thermoradiotherapy of breast cancer. Int J Hyperthermia. 2010; 26: 699709. Ref.: https://goo.gl/yNL1bH 